Check for updates

Cite this: RSC Adv., 2018, 8, 20996

\title{
Utilization of a nonionic surfactant for improved corrosion resistance of carbon steel in simulated fuel-grade ethanol
}

\begin{abstract}
M. A. Deyab (iD *
In this study, a nonionic surfactant (PEG-40 hydrogenated castor oil, Abbrev. PEG-40 HCO) was used to improve the corrosion resistance of carbon steel in simulated fuel-grade ethanol (SFGE). The studies were conducted using cyclic voltammetry (CV) and potentiodynamic polarization techniques and complemented by scanning electron microscopy (SEM) investigations. The presence of water and chloride ions in SFGE strongly influences the electrochemical behavior of carbon steel. Polarization curves indicate that PEG-40 HCO has good inhibition efficiency and behaves as a mixed inhibitor. The inhibition efficiency increases with the concentration of PEG-40 HCO within the range of 20 to 100 ppm, reaching a maximum value of $93.8 \%$. The adsorption of PEG-40 HCO obeys the Langmuir adsorption isotherm. Quantum chemical calculations were evaluated to confirm experimental results.
\end{abstract}

Received 5th April 2018

Accepted 30th May 2018

DOI: $10.1039 / c 8 r a 02936 a$

rsc.li/rsc-advances

In order to achieve these objectives, cyclic voltammetry and

\section{Introduction}

The increasing need for alternative energy has propelled the search for new resources, and one of these is ethanol. ${ }^{1}$ With the increasing demand for ethanol, fast, cheap and safe transportation by pipelines is needed to satisfy the demand. However, pipeline transport of ethanol poses potential problems due to corrosion-related damage..$^{2-4}$ Previous studies of metallic materials in methanol and ethanol show that significant pitting corrosion can be initiated in these alcoholic solvents. ${ }^{5,6}$ These corrosion failures can strongly cause degradation of in-service equipment, in either the pipeline transportation industry or fuel manufacturing industry. The corrosiveness of the fuel ethanol depends on the content and types of contaminants. Water and chloride ions are expected to be present as contaminants in small amounts in commercial fuel ethanol and may affect the corrosion behavior of the materials it comes into contact with. ${ }^{7}$

Prevention of the corrosion in ethanol is possible by creating a barrier between the steel surface and the ethanol. The selection of the proper inhibitor must be done carefully because the selected inhibitor may emulsify and/or foam. The inhibitor should have adequate properties to adsorb to the steel surface to form a strong barrier film. ${ }^{8-10}$

In this study, nonionic surfactant (PEG-40 HCO) was tested as cheap, non-toxic and environmentally acceptable inhibitor for carbon steel corrosion in SFGE. PEG-40 HCO is a non-ionic surfactant which enables oils to be solubilized into the water.

Egyptian Petroleum Research Institute (EPRI), PO Box 11727, Nasr City, Cairo, Egypt. E-mail: hamadadeiab@yahoo.com; Fax: +20222747433; Tel: +201006137150 potentiodynamic polarization methods besides quantum chemical calculations were carried out in this study. Some SEM examinations of the electrode surface have been carried out.

\section{Experimental details}

Specimen of carbon steel with chemical composition (wt\%), $0.06 \mathrm{C} ; 0.06 \mathrm{Si} ; 0.7 \mathrm{Mn} ; 0.005 \mathrm{P} ; 0.001 \mathrm{~S} ; 0.012 \mathrm{Ni} ; 0.015 \mathrm{Cr} ; 0.004$ Mo; $0.002 \mathrm{~V} ; 0.02 \mathrm{Cu}$ and $99.12 \mathrm{Fe}$, were machined to obtain cylindrical electrode, which it was sealed in epoxy resin, with a circular cross-section area $\left(0.45 \mathrm{~cm}^{2}\right)$ exposed to the electrolyte. Before each experiment, this electrode was mechanically polished with emery paper up to 600 grit, rinsed with distilled water, alcohol and acetone and dried.

The chemical composition of the simulated fuel-grade ethanol SFGE based on ASTM D-4806 used in this study is composed of $98.5 \mathrm{vol} \%$ of ethanol, $0.5 \mathrm{vol} \%$ methanol, $1.0 \mathrm{vol} \%$ of water, $56 \mathrm{ppm}$ of acetic acid and $32 \mathrm{ppm} \mathrm{NaCl}{ }^{11}$ The physicochemical characteristics of the ethanol SFGE are listed in Table 1.

The nonionic surfactant, namely PEG-40 hydrogenated castor oil PEG-40 $\mathrm{HCO} \mathrm{C}_{57} \mathrm{H}_{110} \mathrm{O}_{9}\left(\mathrm{CH}_{2} \mathrm{CH}_{2} \mathrm{O}\right)_{n}$ where $n=40$, was obtained from Cationa Chemical Corporation Company.

$\mathrm{CV}$ and potentiodynamic polarization studies were carried out using a potentioscan type (Potentiostat/Galvanostat EG\&G model 273) connected with a personal computer. A platinum foil was used as the auxiliary electrode, $\mathrm{Ag} / \mathrm{Ag}$ Cl electrode (SSCE) in which the outer compartment is filled with $1.0 \mathrm{M} \mathrm{LiCl}$ in ethanol was used as the reference electrode. The reference electrode (SSCE) separated from the test solution by Vycor junction (frit) that serves as a salt bridge. The liquid junction 
Table 1 The physicochemical characteristics of the ethanol SFGE

\begin{tabular}{lll}
\hline Property & Unit & SFGE \\
\hline Appearance & - & Colorless liquid \\
Odor & - & Alcoholic odor \\
Physical state & - & Liquid \\
Boiling point & ${ }^{\circ} \mathrm{C}$ & 77 \\
Viscosity at $25{ }^{\circ} \mathrm{C}$ & $\mathrm{mPa} \mathrm{s}$ & 1.089 \\
Density at $20^{\circ} \mathrm{C}$ & $\mathrm{g} \mathrm{cm}{ }^{-3}$ & 0.828 \\
Solubility in water & - & Miscible \\
Refractive index & - & 1.3823 \\
Water content & $\mathrm{wt} \%$ & 1.0 \\
Methanol content & $\mathrm{wt} \%$ & 0.5 \\
Acetic acid content & $\mathrm{ppm}$ & 56 \\
NaCl content & $\mathrm{ppm}$ & 32 \\
pH & - & 5.7
\end{tabular}

potential was not taken in account since that the experiments were performed comparatively in absence and in the presence of the corrosion inhibitor. All the experiments were carried out at a scan rate $1.0 \mathrm{mV} \mathrm{s}^{-1}$. The $\mathrm{CV}(E-j)$ curves were recorded by sweeping linearly the potential from the starting potential $(-1.0$ $\mathrm{v}$ ) into the positive direction till a required potential value and then reversed with the same scan rate till the starting potential to form one complete cycle. Potentiodynamic polarization curves were obtained by changing the electrode potential automatically from -250 to $+250 \mathrm{mV}$ versus open circuit potentials. The logarithmic current density was plotted against the electrode potential. These polarization curves exhibit Tafeltype behavior.

The morphology of the carbon steel surface of some samples was determined after the desired electrochemical tests by employing scanning electron microscopy (SEM). SEM was performed using a JEOL/Quantek detector.

All solutions were prepared from analytical grade chemical reagents using doubly distilled water and were used without further purification.

The solutions temperatures were adjusted to within $\pm 0.2{ }^{\circ} \mathrm{C}$ using a water thermostat.

Quantum chemical calculations were performed depends on the based density function theory (DFT) in Materials Studio 6.0 using VAMP module and Accelrys software. The Quantum parameters such as the energy of the highest occupied molecular orbital $\left(E_{\mathrm{HO} о}\right)$, the energy of the lowest unoccupied molecular orbital ( $\left.E_{\mathrm{LUMO}}\right)$, energy gap $(\Delta E)$ between LUMO and HOMO and were calculated.

\section{Results and discussion}

\subsection{Electrochemical profile of carbon steel in SFGE and effect of water}

In order to ascertain the electrochemical profile of carbon steel in SFGE, CV experiments were performed to characterize the reduction and oxidation processes on the metal surface. Fig. 1 shows the cyclic voltammogram of carbon steel in SFGE in the absence and presence of different concentration of water. The cyclic voltammetric scan started at $-1.0 \mathrm{~V}$ versus SCE and was swept first in the anodic direction. Inspection of the data reveals

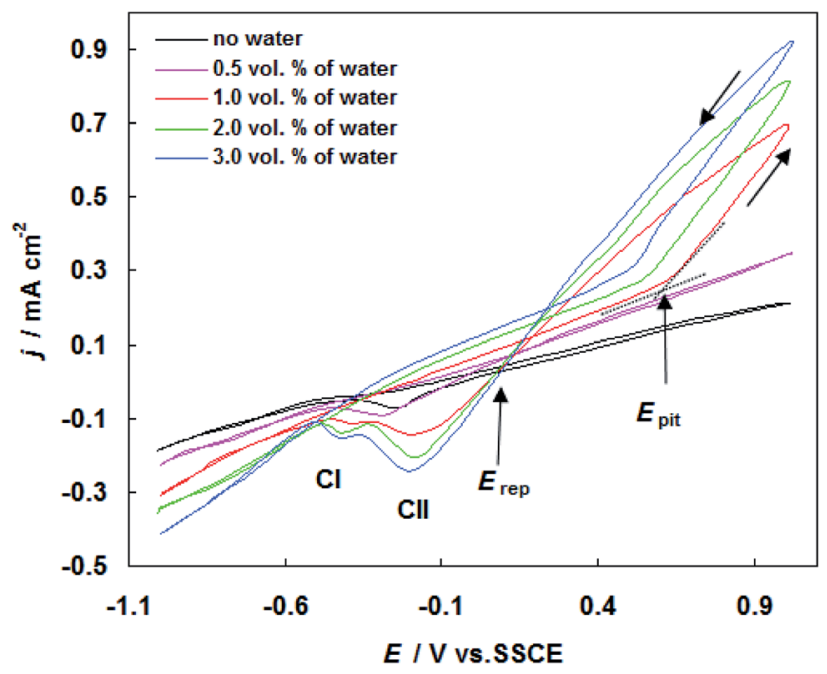

Fig. 1 Cyclic voltammograms for carbon steel in SFGE in the absence and presence of different concentration of water at $298 \mathrm{~K}$.

that, on positive going sweep, the cathodic current decreases continually and changes its sign at corrosion potential $\left(E_{\text {corr }}\right)$.

In the absence of water the electrooxidation of the metal was visible from $-0.10 \mathrm{~V}$ to $1.0 \mathrm{~V}$ versus SCE. The addition of water to SFGE led to the shifting of the electrodissolution of the metal to more negative values (i.e. $-0.162 \mathrm{~V},-0.260 \mathrm{~V},-0.306 \mathrm{~V}$ and $-0.355 \mathrm{~V}$ versus SCE).

Data in Fig. 1 shows that the carbon steel in alcoholic solvent, usually exhibits a poor passivity. ${ }^{12}$ This means that anodic polarization curves display active electrochemical behavior without the formation of an oxide protective film (passive layer) on the metal surface.

When the curve sweeping back in the reverse direction, the cathodic sweep exhibits one cathodic peak (CI), which are probably related to the reduction of hydrogen and iron oxides. It clear form Fig. 1 that the anodic current density values increased in the presence of water. No distinguishable pits are found on the carbon steel surface exposed to the SFGE with less than 0.5 vol\% water. As the water content increases from 1.0 to $3.0 \mathrm{vol} \%$, the cyclic voltammograms of carbon steel in SFGE remarkable changes. It is observed that at a certain critical potential (pitting potential $E_{\text {pit}}$ ), the anodic current density increases steeply without any sign for oxygen evolution. The rapid rise in anodic current density at $E_{\text {pit }}$ indicates initiation and growth of pitting attack. ${ }^{13}$

At the reversing the potential sweep, the reverse (pitting) current exhibits a positive hysteresis loop. This represents the property of pitting corrosion. This indicates also that pitting process continues even after scan reversal, because of the autocatalytic character of pitting. The presence of hysteresis loop in CV curve elucidates a retard in repassivation process when the potential is reversed toward the negative direction. Upon reversing scan, the pitting current reaches to zero values at a certain potential known as the repassivation potential $\left(E_{\text {rep }}\right){ }^{14}$ In this stage, all pits become repassivate. ${ }^{14}$ The repassivation process could be achieved by removal of accumulated $\mathrm{Cl}^{-}$ions from the pits by diffusion. ${ }^{14}$ 
At the reversing scan, the potential is scanned negatively to cause the reduction processes. The corresponding peaks $\mathrm{CI}$ and $\mathrm{CII}$ are due to the reduction of corrosion product and pitting corrosion products precipitate on the electrode surface, respectively.

It is clear also that the values of $E_{\text {pit }}$ move in the active direction, with increase in water concentration from 1.0 to $3.0 \mathrm{vol} \%$. Effect of water in non-aqueous solvents, such as ethanol, has been widely studied. Some researchers have concluded that the greater solubility of corrosion product and increase of the hydrated proton concentration in presence of water result in aggressive general and pitting corrosion. ${ }^{15,16}$ The influence of water on pitting corrosion susceptibility of carbon steel in SFGE is mainly due to the ethanol/water solvation and the balance between the surface passivation reactions and the passivity breakdown in such system.

The scanning electron microscope was used to characterize the carbon steel surface after the CV test in SFGE before and beyond $E_{\mathrm{pit}}$. No distinguishable pits are observed on the metal surface exposed to the SFGE before $E_{\text {pit }}$ under the scanning electron microscope (see image a in Fig. 2). Beyond $E_{\text {pit }}$ SEM observations reveal the presence of pits on the metal surface after removing the corrosion products (see image b in Fig. 2). These observations comply with electrochemical data, where the oxide layer beyond $E_{\text {pit }}$ becomes very weak and this leads to the initiation of pitting corrosion on the metal surface. In this case, the breakdown of oxide film is due to the adsorption of $\mathrm{Cl}^{-}$ ions on the oxide film, forming an electric field between the oxide/SFGE interfaces. At $E_{\text {pit }}$ value, the adsorbed $\mathrm{Cl}^{-}$ions penetrate the oxide film and form pits.

The results of cyclic voltammograms of carbon steel in SFGE containing $1.0 \mathrm{vol} \%$ water in the presence of different concentrations of chloride ions are shown in Fig. 3. The data of Fig. 3 clearly show that, the anodic current density value increases with increasing $\mathrm{Cl}^{-}$ion concentration, indicating the aggressiveness of $\mathrm{Cl}^{-}$ion toward the corrosion process of carbon steel. This behavior could be attributed to the formation of the soluble complex between $\mathrm{Fe}^{2+}$ and $\mathrm{Cl}^{-}$ion. ${ }^{17}$ Such complexing processes lead to a further decrease in the free $\mathrm{Fe}^{2+}$ ion concentration at the electrode surface. The $\mathrm{Cl}^{-}$ions can be adsorbed on the bare metal surface in competition with $\mathrm{OH}^{-}$ ions. As a result of high polarizability of the $\mathrm{Cl}^{-}$ions, the $\mathrm{Cl}^{-}$ ions may adsorb preferentially. ${ }^{18}$ The adsorbed $\mathrm{Cl}^{-}$ions can penetrate through the metal surface layer especially at its point defects and flaws and initiate pitting. ${ }^{18}$ Moreover an increase in
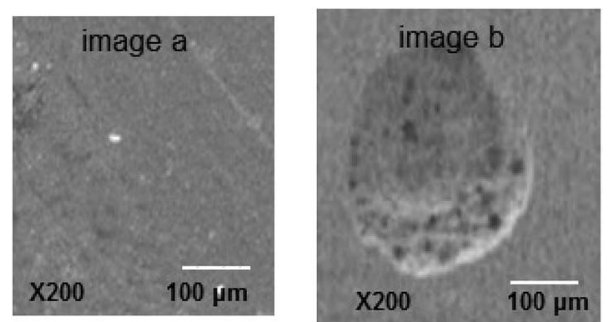

Fig. 2 SEM micrographs of the electrode surface in SFGE containing 3.0 vol\% water before (image a) and after (image b) $E_{\text {pit. }}$.

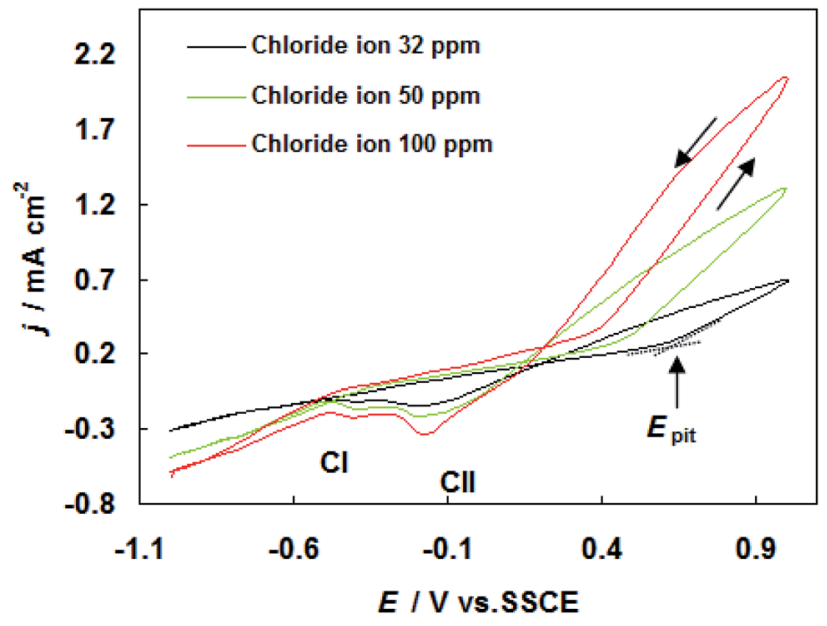

Fig. 3 Cyclic voltammograms for carbon steel in SFGE containing $1.0 \mathrm{vol} \%$ water in the presence of different concentrations of chloride ions at $298 \mathrm{~K}$.

$\mathrm{Cl}^{-}$ions concentration shifts the pitting potentials toward a more negative (active) direction corresponding to decrease the resistance to pitting. The dependence of the pitting potential on the concentration of chloride ions is given in Fig. 4 which shows $E_{\text {pit }} v s . \log \left[\mathrm{Cl}^{-}\right]$whereby a straight line obtained according to the following equation:

$$
E_{\text {pit }}=a-b \log \left[\mathrm{Cl}^{-}\right]
$$

where $a$ and $b$ are constants depending on the metal composition, electrolyte composition, etc. From eqn (1) it is possible to estimate the maximum chloride level above which pitting is expected to occur immediately in relevant environment.

It is obvious to observe from Fig. 3 that an increase in $\mathrm{Cl}^{-}$ion concentration increases the current density of the two cathodic peaks (CI and CII).

\subsection{The effect of PEG-40 HCO}

The corrosion behavior of carbon steel in SFGE in the absence and presence of PEG-40 HCO was investigated by potentiodynamic

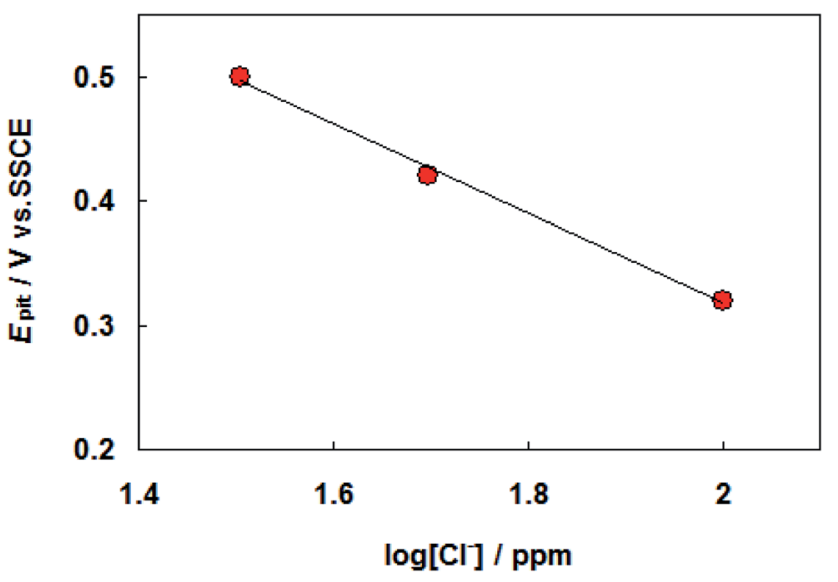

Fig. 4 Relation between $E_{\text {pit }}$ versus $\log \left[\mathrm{Cl}^{-}\right]$for carbon steel in SFGE. 
polarization method. Tafel polarization curves for carbon steel at $298 \mathrm{~K}$ in SFGE in the absence and presence of different concentration of PEG-40 HCO are given in Fig. 5. Table 2 shows the electrochemical corrosion kinetic parameters, i.e. corrosion potential ( $\left.E_{\text {corr }}\right)$ and corrosion current density $\left(j_{\text {corr }}\right)$ obtained from the Tafel extrapolation of the polarization curves. Table 2 also included percentage inhibition efficiency $\left(\eta_{\mathrm{j}} \%\right)$. The inhibition efficiency $\eta_{\mathrm{j}} \%$ was obtained from the following equation: ${ }^{19}$

$$
\eta_{\mathrm{j}} \%=\frac{j_{\text {corr }(0)}-j_{\text {corr }}}{j_{\text {corr }(0)}} \times 100
$$

where $j_{\text {corr(o) }}$ and $j_{\text {corr }}$ are the uninhibited and inhibited corrosion current densities, respectively. These results show that the inhibition efficiency increased, while the corrosion current density decreased with the addition of PEG-40 HCO. The data clearly show that the addition of PEG-40 HCO shift $E_{\text {corr }}$ to more positive values. An inhibitor can be classified as cathodic or anodic if the difference in corrosion potential is more than $85 \mathrm{mV}$ with respect to the $E_{\text {corr }}$ of the blank. ${ }^{20}$ Such results will indicate that the PEG-40 HCO act as a mixed-type inhibitor with predominant anodic effectiveness. These results show that the PEG-40 HCO can retard both anodic and cathodic reactions. ${ }^{21}$ The inhibition efficiency afforded by PEG-40 HCO may be attributed to the adsorption of this compound at the metal/ corrosive solution interface. The adsorption process takes place via ion pair and ion exchange mechanism by its ethylene oxide groups while its hydrophobic chain are oriented towards the corrosive medium. ${ }^{22}$

The adsorbed PEG-40 HCO molecules on the metal surface may form a surface film, which acts as a physical barrier to restrict diffusion of ions to or from the metal surface and hence retard the corrosion process. The interactions of the adsorbed PEG-40 HCO molecules with surface metal atoms may prevent the metal atoms from participating the anodic reaction of corrosion. This simple blocking effect decreases

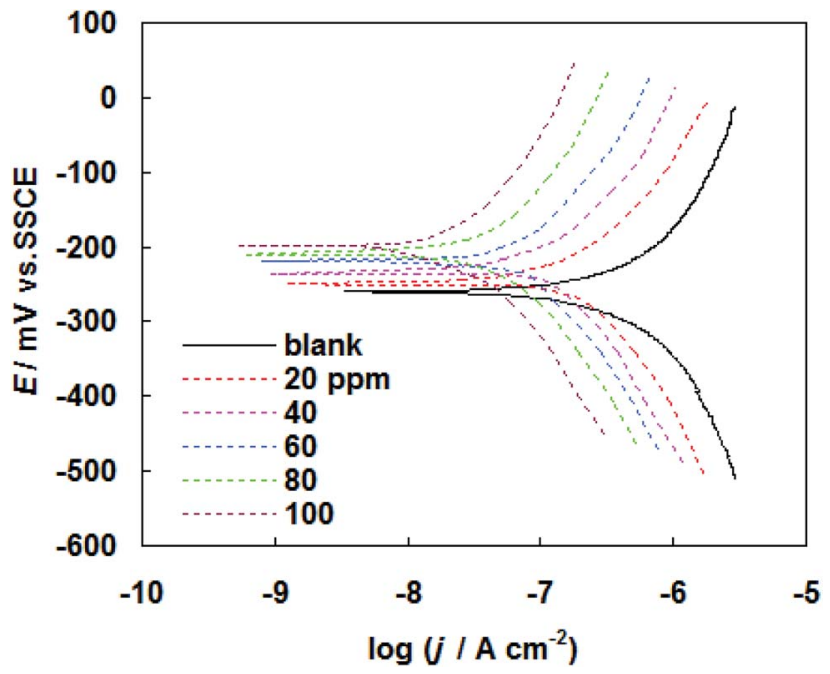

Fig. 5 Tafel polarization curves for carbon steel at $298 \mathrm{~K}$ in SFGE in the absence and presence of different concentration of PEG-40 HCO.
Table 2 Electrochemical parameters and the corresponding inhibition efficiency of PEG-40 HCO for carbon steel in SFGE in the absence and presence of different concentration of PEG-40 HCO at $298 \mathrm{~K}$

\begin{tabular}{llll}
\hline PEG-40 HCO, ppm & $E_{\text {corr }}, \mathrm{mV}(\mathrm{SSCE})$ & $j_{\text {corr }}, \mathrm{nA} \mathrm{cm}^{-2}$ & $\eta_{\mathrm{j}} \%$ \\
\hline Blank & -260 & 630 & - \\
20 & -248 & 263 & 58.2 \\
40 & -235 & 190 & 69.8 \\
60 & -219 & 141 & 77.5 \\
80 & -212 & 96 & 84.7 \\
100 & -198 & 39 & 93.8 \\
\hline
\end{tabular}

the number of surface metal atoms participating and hence decreases corrosion. It has been observed that the inhibition efficiency increased with increase in surface coverage by inhibitor molecules. The high inhibition efficiency is due to the bonding of adsorbed PEG-40 HCO molecules on to the metals. The strong bonding is mainly attributed to higher number of ethylene oxide group, present in the adsorbate molecules. ${ }^{23}$

\subsection{Adsorption considerations}

Basic information on the interaction between the PEG-40 HCO molecules and carbon steel surface in SFGE can be provided using the adsorption isotherm. For this purpose, the values of surface coverage $\left(\theta=\eta_{\mathrm{j}} \% / 100\right)$ at different concentrations of PEG-40 HCO in SFGE at $298 \mathrm{~K}$ were calculated to explain the best isotherm to determine the adsorption process from the experimental data obtained. Attempts were made to fit these $\theta$ values to various isotherm including Frumkin, Langmuir, Temkin, Freundlich isotherms. By far the best fit is obtained with the Langmuir isotherm. Langmuir adsorption isotherm is described by the following equation: ${ }^{24}$

$$
\frac{C_{\mathrm{inh}}}{\theta}=\frac{1}{K_{\mathrm{ads}}}+C_{\mathrm{inh}}
$$

where $K_{\text {ads }}$ is the equilibrium constant of the adsorption reaction, $C_{\mathrm{inh}}$ is the inhibitor concentration in the bulk of the solution.

Fig. 6 shows the relationship between $\left(C_{\mathrm{inh}} / \theta\right)$ and $C_{\mathrm{inh}}$. The obtained plot shows that the linear correlation coefficients $\left(R^{2}\right.$ $=0.9867$ ) are almost equal to unity and the slope of line are very close to unity (slope $=0.992$ ), which indicates that the adsorption of PEG-40 HCO on the carbon steel surface in SFGE follows Langmuir adsorption isotherm..$^{25}$

The value of adsorption equilibrium constant $K_{\text {ads }}$ is calculated from the reciprocal of the intercept of the isotherm line as $4.6 \times 10^{4} \mathrm{M}^{-1}$. $K_{\text {ads }}$ that is related to the standard free energy of adsorption $\left(\Delta G_{\text {ads }}^{0}\right)$ by: ${ }^{26,27}$

$$
\Delta G_{\mathrm{ads}}^{0}=-R T \ln \left(55.5 K_{\mathrm{ads}}\right)
$$

where $R$ is the molar gas constant, $T$ is the absolute temperature and 55.5 is the concentration of water in solution expressed in molar. 


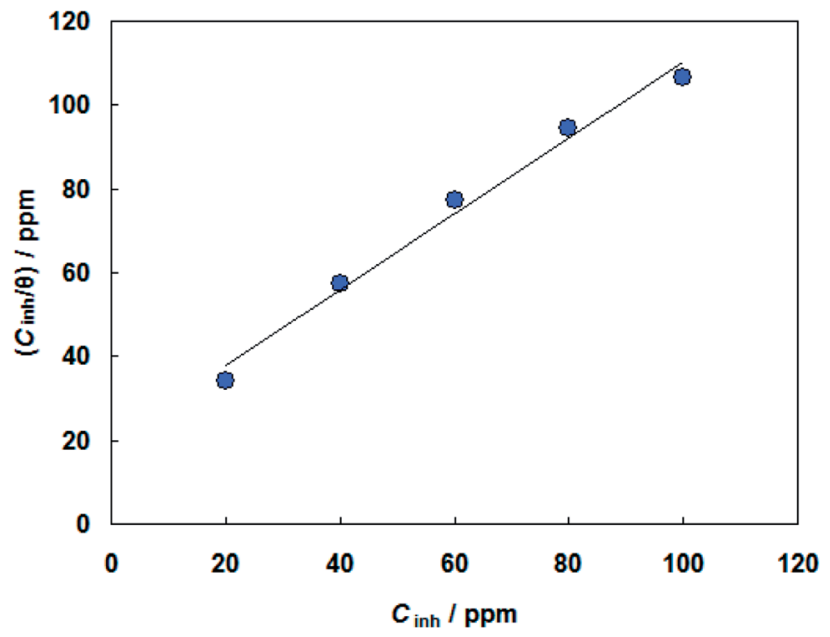

Fig. 6 Langmuir's adsorption isotherm plot for the adsorption of PEG$40 \mathrm{HCO}$ in SFGE.

The values of the free energy of adsorption $\Delta G_{\text {ads }}^{0}$ as calculated from the Langmuir adsorption isotherm was $-36.5 \mathrm{~kJ} \mathrm{~mol}^{-1}$. The negative value of $\Delta G_{\mathrm{ads}}^{0}$ ensures the spontaneity of the adsorption of PEG-40 HCO on the carbon steel surface in SFGE. ${ }^{28}$

\subsection{Activation energy and heat of adsorption}

The effect of increase in solution temperature from 298 to $323 \mathrm{~K}$ on $j_{\text {corr }}$ and $\theta$ is summarized in Table 3.

The apparent activation energy $E_{\mathrm{a}}$ of the corrosion reaction was calculated using the Arrhenius equation: ${ }^{29}$

$$
\log \left(j_{\text {corr } 2} / j_{\text {corr } 1}\right)=E_{\mathrm{a}} / 2.303 R\left[\left(1 / T_{1}\right)-\left(1 / T_{2}\right)\right]
$$

where $j_{\text {corr1 }}$ and $j_{\text {corr2 }}$ are the corrosion current densities at temperature $T_{1}$ and $T_{2}$, respectively.

An estimate of heat of adsorption $Q_{\text {ads }}$ was obtained from the trend of surface coverage $\theta$ with temperature as follows: ${ }^{30}$

$$
Q_{\mathrm{ads}}=2.303 R\left[\log \left(\theta_{2} / 1-\theta_{2}\right)-\log \left(\theta_{1} / 1-\theta_{1}\right)\right] \times\left(T_{1} T_{2} / T_{2}-T_{1}\right)
$$

where $\theta_{1}$ and $\theta_{2}$ are the degrees of surface coverage at temperatures $T_{1}$ and $T_{2}$. The calculated values for $E_{\mathrm{a}}$ and $Q_{\text {ads }}$ are given in Table 3.

As it can be seen from Table 3, that the rates of carbon steel corrosion in presence of steel in the simulated fuel-grade ethanol increased with temperature while the inhibition efficiency decreased.

From the Table 3, it is clear that the lower values of $E_{\text {a }}$ obtained in presence of PEG-40 HCO compared with those

Table 3 The values of corrosion current densities $\left(j_{\text {corr }}\right)$, degrees of surface coverage $(\theta)$, activation energy $\left(E_{\mathrm{a}}\right)$ and heat of adsorption $\left(Q_{\text {ads }}\right)$ for carbon steel in SFGE in the absence and presence of different concentration of PEG-40 HCO at 298 and $323 \mathrm{~K}$

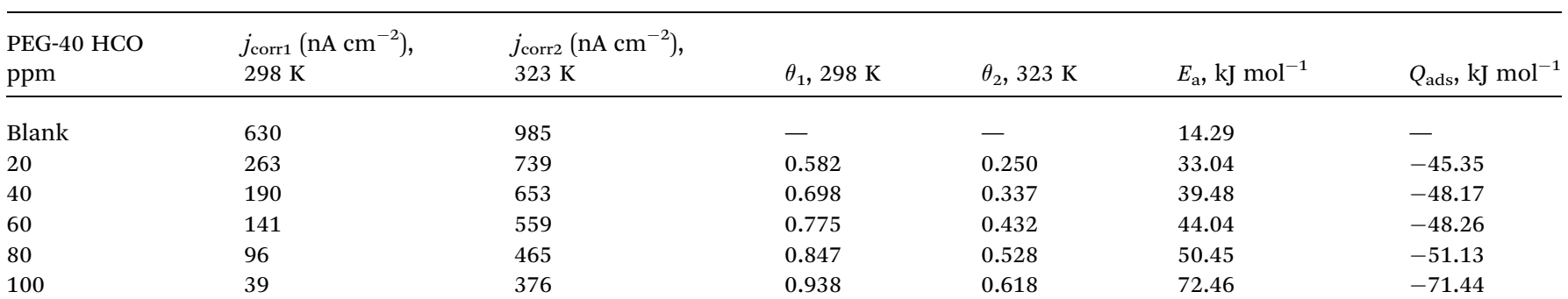

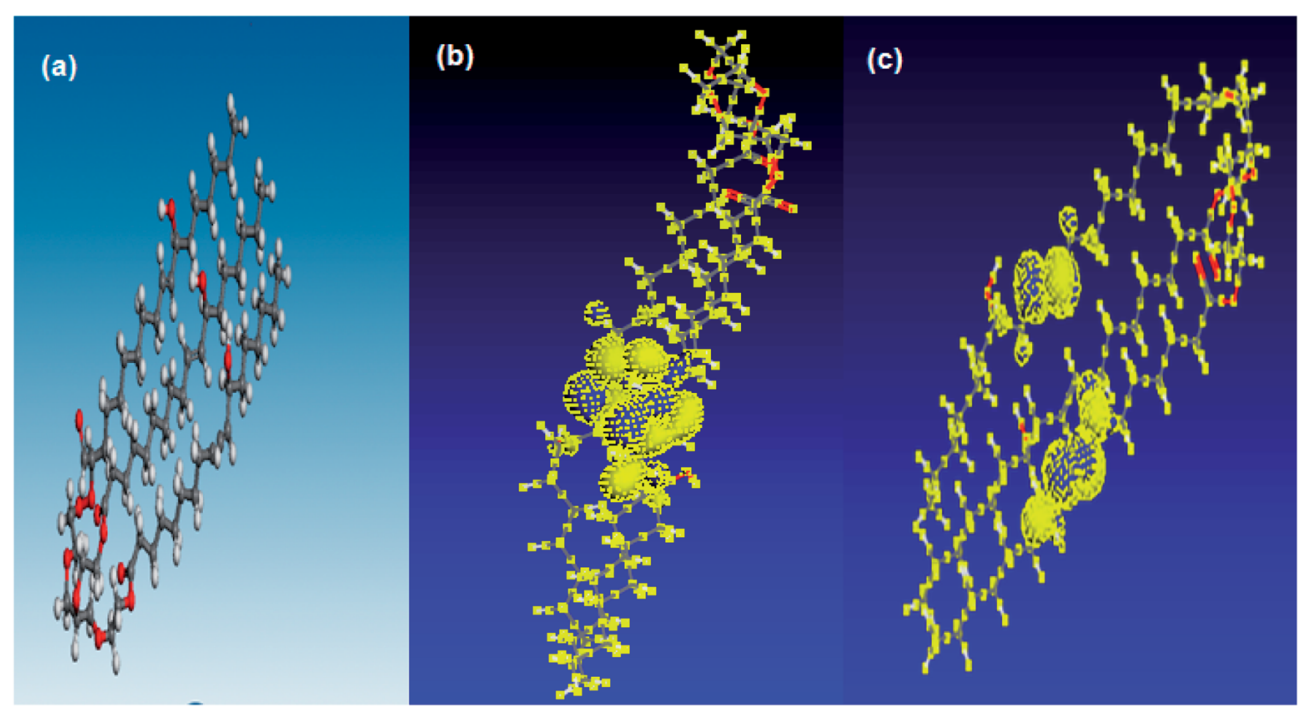

Fig. 7 (a) The optimized geometry, (b) HOMO, (c) LUMO density distribution for PEG-40 HCO. 
obtained in its absence can be attributed to its physical adsorption on the metal surface. ${ }^{31}$ Additionally, since $Q_{\text {ads }}$ have negative values, it can be concluded that the degree of surface coverage by PEG-40 HCO molecule decreased with rise in temperature. ${ }^{31}$ This can be interpreted on the basis that increasing temperature leads to the desorption of some adsorbed PEG-40 HCO molecule from the carbon steel surface.

\subsection{Quantum chemical calculations}

Fig. 7 shows the optimized geometry, HOMO, LUMO density distribution for PEG-40 HCO. The zones of the HOMO are the sites liable to electrophilic attack and represent the active centers for the adsorption process. LUMO zones (anti-bonding orbital) can receive electrons from Fe d-orbital. ${ }^{32}$ The high value of $E_{\mathrm{HOMO}}\left(E_{\mathrm{HOMO}}=\right.$ $-9.024 \mathrm{eV}$ ) refers to the ability of the PEG-40 HCO molecule to give electrons to empty d-orbitals of Fe atom to form coordinate bond. ${ }^{33}$ On other hand, the low value of $E_{\mathrm{LUMO}}\left(E_{\mathrm{LUMO}}=-0.644 \mathrm{eV}\right)$ confirm the ability of the PEG-40 HCO molecule to accept electrons from filled Fe d-orbital. Based on the above data, it clears that The $E_{\mathrm{HOMO}}$ and $E_{\mathrm{LUMO}}$ are related to the degree of adsorption of PEG-40 HCO molecule on the Fe surface. Where the low value of $\Delta E(\Delta E=$ $8.38 \mathrm{eV}$ ) provides good inhibition efficiency. ${ }^{34}$ These theoretical calculations agree well with the data obtained experimentally.

\section{Conclusions}

(1) Electrochemical measurements (cyclic voltammetry and potentiodynamic polarization) were devoted to test the corrosion behavior of carbon steel in the simulated fuel-grade ethanol SFGE and the inhibition characters of PEG-40 HCO.

(2) Voltammetry shows that the anodic current density value enhances and $E_{\text {pit }}$ move in the active direction with increasing water and chloride ions concentration.

(3) SEM images confirmed the existence of pits on the carbon steel surface exposed to SFGE, as the water content increases from 1.0 to 3.0 vol\%.

(4) The results obtained form Tafel curves indicate that PEG-40 HCO has good inhibition efficiency for carbon steel in SFGE.

(5) The inhibition effect of PEG-40 HCO is due to its physical adsorption on the carbon steel surface. The adsorption follows Langmuir adsorption isotherm.

(6) The degree of surface coverage by PEG-40 HCO decreased with temperature.

(7) Both experimental and quantum chemical calculations are in excellent agreement.

\section{Conflicts of interest}

There are no conflicts to declare.

\section{References}

1 C. A. Cardona and Ó. J. Sánchez, Bioresour. Technol., 2007, 98, 2415-2457.
2 N. Sridhar, K. Price, J. Buckingham and J. Dante, Corrosion, 2006, 62, 687-702.

3 J. G. Maldonado and N. Sridhar, SCC of carbon steel in fuel ethanol service, in: Effect of Corrosion Potential and Ethanol Processing Source, Corrosion 2007, NACE International, 2007, Nashville, TN, Paper No. 07574.

4 X. Lou, D. Yang and P. Singh, Corrosion, 2009, 65, 785797.

5 X. Lou and P. M. Singh, Corros. Sci., 2010, 52, 23032315.

6 E. Heitz, Adv. Corros. Sci. Technol., 1974, 4, 149-243.

7 H. D. M. Avelar and P. J. S. Barbeira, Fuel, 2007, 86, 299-302.

8 M. A. Deyab, J. Taiwan Inst. Chem. Eng., 2016, 60, 369375.

9 M. A. M. Deyab, J. Surfactants Deterg., 2015, 18, 405-411.

10 M. A. Deyab, B. El Bali, R. Essehli, R. Ouarsal, M. Lachkar and H. Fuess, J. Mol. Liq., 2016, 216, 636-640.

11 ASTM International, ASTM 4806, West Conshohocken, PA, USA, 2010.

12 J. Banas, B. Stypula, K. Banas, J. Swiatowska-Mrowiecka, M. Starowicz and U. Lelek-Borkowska, J. Solid State Electrochem., 2009, 13, 1669.

13 M. A. Deyab, Electrochim. Acta, 2016, 202, 262-268.

14 M. A. Deyab, J. Solid State Electrochem., 2009, 13, 1737-1742.

15 J. Banas, Electrochim. Acta, 1987, 32, 871-875.

16 C. S. Brossia, E. Gileadi and R. G. Kelly, Corros. Sci., 1995, 37, 1455-1471.

17 Z. Szklarska-Smialowska, Pitting corrosion of metals, NACE, Houston, 1986.

18 M. A. Deyab, Desalination, 2016, 384, 60-67.

19 M. A. Deyab, R. Essehli and B. El Bali, RSC Adv., 2015, 5, 48868-48874.

20 S. John, A. Joseph, T. Sajini and A. J. Jose, Egypt. J. Pet., 2017, 26, 721-732.

21 M. A. Deyab, RSC Adv., 2016, 6, 32514-32518.

22 M. A. Deyab, H. A. Abo Dief, E. A. Eissa and A. R. Taman, Electrochim. Acta, 2007, 52, 8105-8110.

23 A. O. Yüce and G. Kardaș, Corros. Sci., 2012, 58, 86-94.

24 M. A. Deyab, R. Ouarsal, M. Lachkar, B. El Bali and R. Essehli, J. Mol. Liq., 2016, 219, 994-999.

25 E. E. Oguzie, V. O. Njoku, C. K. Enenebeaku, C. O. Akalezi and C. Obi, Corros. Sci., 2008, 50, 3480-3486.

26 M. A. Deyab, R. Essehli and B. El Bali, RSC Adv., 2015, 5, 64326-64334.

27 S. A. Umoren, I. B. Obot, E. E. Ebenso, P. C. Okafor, O. Ogbobe and E. E. Oguzie, Anti-Corros. Methods Mater., 2006, 53, 277-282.

28 E. E. Oguzie, Port. Electrochim. Acta, 2008, 26, 303-314.

29 M. A. Deyab, J. Taiwan Inst. Chem. Eng., 2016, 58, 536-541.

30 M. A. Deyab, K. Eddahaoui, R. Essehli, T. Rhadfi, S. Benmokhtar and G. Mele, Desalination, 2016, 383, 38-45. 31 E. E. Oguzie, Mater. Chem. Phys., 2004, 87, 212-217.

32 V. S. Sastri and J. R. Perumareddi, Corrosion, 1997, 53, 617-622. 33 S. Martinez, Mater. Chem. Phys., 2003, 77, 97-102.

34 M. J. Bahrami, S. M. A. Hosseini and P. Pilvar, Corros. Sci., 2010, 52, 2793-2803. 